\title{
Modeling of Runoff using Curve Expert for Dachigam-Telbal Catchment of Kashmir Valley, India
}

\author{
Mehlath Shah, Syed Midhat Fazil, Syed Rouhullah Ali*, Yogesh Pandey, \\ Shahzad Faisal and Iqra Mehraj
}
Division of Agricultural Engineering, Sher-e-Kashmir University of Agricultural Sciences and Technology of Kashmir-190025, India
*Corresponding author

\section{A B S T R A C T}

\begin{tabular}{|l|}
\hline Ke y w o r d s \\
Catchment, Curve \\
expert 2.0, Rainfall, \\
$\begin{array}{l}\text { Regression analysis, } \\
\text { Runoff. }\end{array}$ \\
\hline Article Info \\
\hline $\begin{array}{l}\text { Accepted: } \\
\text { 28 September } 2017 \\
\text { Available Online: } \\
\text { 10 November } 2017\end{array}$ \\
\hline
\end{tabular}

The study were attempted to develop prediction models for runoff using rainfall as single predictor. An outline for a complete synthetic rainfall-runoff database was developed to study catchment response to a variety of rainfall events. DachigamTelbal catchment was chosen as study site and records of rainfall amount and runoff were organized and analyzed. For runoff, regression analysis was done in different ways to develop model that can predict runoff by using rainfall as single variable as it is one hydrological parameter which is recorded in most parts of the country. Curve expert 2.0 was used to generate these models. The attempt to develop runoff prediction model with rainfall as single input variable, exhibited high promise for monthly analysis with higher value of coefficient of determination i.e. $\mathrm{R}^{2}=0.95$, and lower standard error of estimation i.e. $\mathrm{S}=0.36$, under regression analysis.

\section{Introduction}

Environmental problems are caused by the increasing number and intensity of floods and flash flood events, taking a high human and economic toll (Smith and Ward, 1998; Villarini et al., 2010). In the pertaining period, numerous new tools and programs for flood forecasting systems and risk management plans have been developed (Chao et al., 2008; Romanowicz et al., 2008; Cloke and Pappenberger, 2009; Tiwari and Chatterjee, 2010; Villarini et al., 2010).Runoff is the most basic and important data needed when planning water control strategies/practices, such as, waterways, storage facilities or erosion control structures (Austin, 2006). The estimation of runoff depends upon number of factors related to rainfall properties, geomorphologic characteristics of catchment and cover management (King, 2000). These parameters are not available readily and thus rainfall amount is used. The rainfall amount can be used as a single input factor determining the volume of runoff for selected catchment (Dachigam-Telbal). Among different hydrologic processes, runoff is a single important process that influences several of the soil and water management decisions and 
therefore runoff is often required to be measured or estimated for a given situation. The magnitude, time distribution and peak rate of runoff are important runoff properties that have important role in design, operation and management of soil and water conservation and development work.

\section{Study area}

Dachigam and Telbal catchments of Dal Lake were taken as the study area. Dal Lake is the second largest lake in the state of Jammu and Kashmir situated between $74^{\circ} 8^{\prime}$ to $74^{\circ} 9^{\prime} \mathrm{E}$ longitude and $34^{\circ} 5^{\prime}$ to $34^{\circ} 6^{\prime} \mathrm{N}$ latitude, at an altitude of $1587 \mathrm{~m}$. A perennial inflow channel, Telbal channel, enters the lake from the north and supplies about $80 \%$ of water to the lake. Towards the south-east side, an outflow channel drains the lake water into the Chount Kula tributary.

The mean depth of the lake is $1.4 \mathrm{~m}$ with a maximum depth up to $6 \mathrm{~m}$. The length of the shore line of the lake is surrounded by high mountains on one side and by an urban area on the other side. The total catchment area of the DalLake works out to be $337.17 \mathrm{~km}^{2}$.

From computation of runoff point of view, the Dal catchment has been divided in following sub-catchments:

Dachigam (catchment A)

Telbal (catchment B)

Lake Hillside (catchment C)

Srinagar North (catchment D)

Srinagar Centre (catchment E)

Dal Lake (catchment F)

The Dachigam and Telbal sub-catchments that constitute the major portion of Dal Lake catchment was selected for the present study. Total area of the catchment is $234.17 \mathrm{~km}^{2}$. The data used in this study were (a) daily rainfall data for the 6 year period (2006-
2011) (b) daily discharge data of the watershed at main outlet for the 6 year period (2006- 2011). The daily rainfall data were collected from AMFU-Srinagar, Division of Agronomy, SKUAST-K and daily discharge date were collected from Lakes and Waterways Development Authority, Kashmir. Curve expert software 2.0.2 was used for predicting run-off using rainfall as single variable. The software is designed with the purpose of generating high quality results and output while saving your time in the process.

\section{Results and Discussion}

The curve expert software was used for regression analysis which was performed by relating mean value of runoff as dependent variable and the amount of rainfall for respective period as independent variable.

The software has several linear, polynomials, and nonlinear inbuilt models which it tested for the supplied data, along with their rank of fitting ability. For a given set of data the first five ranked models were used to predict the runoff.

\section{Monthly analysis data for rainfall-runoff}

The hydrological data of monthly rainfall and corresponding runoff were tried to fit in different models to predict the variation in runoff based on amount of rainfall, in curve expert 2.0.2. Figure 1(a-e) illustrates the each model suggested by the software.

In order to predict the variation in runoff based on amount of rainfall, the hydrological data of monthly rainfall and corresponding runoff were tried to fit in linear regression, shifted power, rational, vapor pressure and heat capacity models. These models indicated 94.4, 94.0, 94.9, 94.7 and 94.8\%variability respectively, in the runoff values due to the rainfall itself. The obtained relationship 
between monthly runoff and rainfall amount for Dachigam-Telbal Catchment is shown in Table 1. This table indicated models of different nature giving best fit to the observed value of runoff, ignoring the effect of other variables relating to catchment, conservation practices. However the perusal of Table 1 reveal Heat Capacity Model as best fit model for monthly analysis with $\mathrm{R}^{2}$ value 0.95 , with the use of model of this nature at least 94.8 percent of variation in runoff can be explained by rainfall alone.

Table.1 Observed relationship between runoff and rainfall amount using monthly data for Dachigam-Telbal catchment

\begin{tabular}{|c|c|c|c|c|c|}
\hline $\begin{array}{c}\text { Name of } \\
\text { model }\end{array}$ & Equation & Coefficient & $\mathbf{S}$ & $\mathbf{R}^{2}$ & $\mathbf{R}$ \\
\hline \multirow{2}{*}{$\begin{array}{c}\text { Linear } \\
\text { Regression } \\
\text { Model }\end{array}$} & \multirow{2}{*}{$Y=a+b x$} & $\mathrm{a}=0.318$ & \multirow{2}{*}{0.360} & \multirow{2}{*}{0.944} & \multirow{2}{*}{0.971} \\
\hline & & $b=0.0598$ & & & \\
\hline \multirow{3}{*}{$\begin{array}{l}\text { Shifted } \\
\text { power } \\
\text { model }\end{array}$} & \multirow{3}{*}{$\mathrm{Y}=a(x-b)^{c}$} & $\mathrm{a}=0.274$ & \multirow{3}{*}{0.358} & \multirow{3}{*}{0.948} & \multirow{3}{*}{0.973} \\
\hline & & $b=8.902$ & & & \\
\hline & & $c=0.735$ & & & \\
\hline \multirow{3}{*}{$\begin{array}{c}\text { Vapor } \\
\text { Pressure } \\
\text { Model }\end{array}$} & \multirow{3}{*}{$Y=\exp \left(a+\frac{b}{x}+\operatorname{cln}(x)\right)$} & $\mathrm{a}=-1.227$ & \multirow{3}{*}{0.359} & \multirow{3}{*}{0.947} & \multirow{3}{*}{0.973} \\
\hline & & $b=-0.107$ & & & \\
\hline & & $\mathrm{c}=6.821$ & & & \\
\hline \multirow{3}{*}{$\begin{array}{c}\text { Heat } \\
\text { Capacity } \\
\text { Model }\end{array}$} & \multirow{3}{*}{$Y=a+b x+\frac{c}{x^{2}}$} & $a=0.740$ & \multirow{3}{*}{0.357} & \multirow{3}{*}{0.948} & \multirow{3}{*}{0.973} \\
\hline & & $b=-0.054$ & & & \\
\hline & & $c=-209.4$ & & & \\
\hline \multirow{4}{*}{$\begin{array}{l}\text { Rational } \\
\text { Model }\end{array}$} & \multirow{4}{*}{$Y=\frac{(a+b x)}{\left(1+c x+d x^{2}\right)}$} & $\mathrm{a}=-2.333$ & \multirow{4}{*}{0.375} & \multirow{4}{*}{0.949} & \multirow{4}{*}{0.974} \\
\hline & & $b=-0.237$ & & & \\
\hline & & $c=0.049$ & & & \\
\hline & & $\mathrm{d}=-0.0002$ & & & \\
\hline
\end{tabular}

Table.2 Mean square error and root mean square error for developed models for monthly analysis

\begin{tabular}{|c|c|c|}
\hline Name of model & MSE & RMSE \\
\hline Linear Regression Model & 0.10 & 0.32 \\
\hline Vapor Pressure Model & 0.74 & 0.86 \\
\hline Shifted Power Model & 0.11 & 0.31 \\
\hline Heat Capacity Model & 0.12 & 0.30 \\
\hline Rational Model & 0.10 & 0.31 \\
\hline
\end{tabular}

$\mathrm{MSE}=$ mean square error, $\mathrm{RMSE}=$ root mean square error 
Fig.1 (a-e) Runoff-Rainfall relationship by using different models for hydrological period of 2006-2011

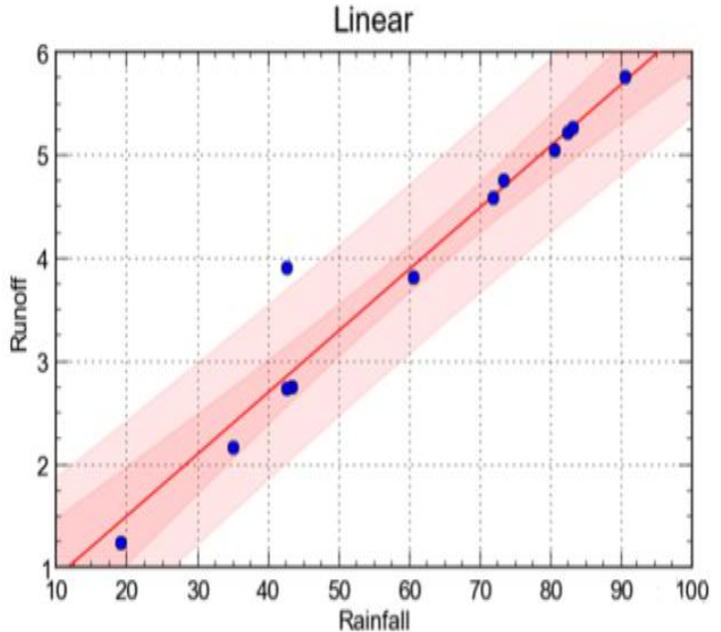

1(a) Linear Model

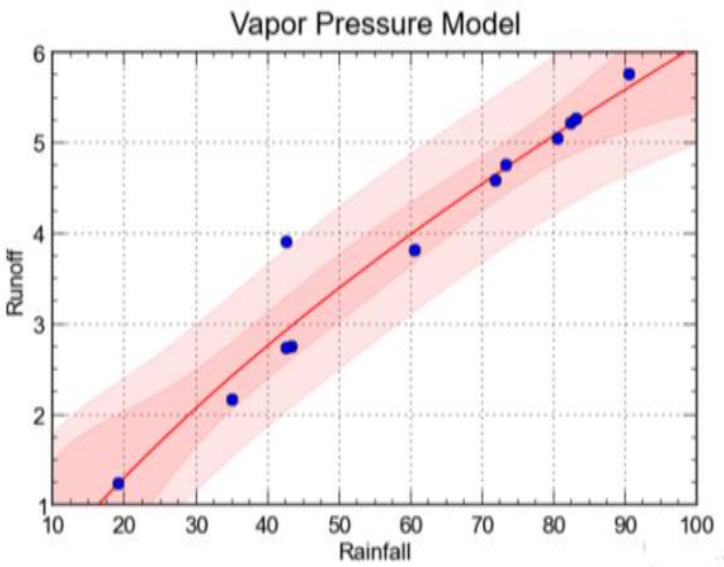

1(c) Vapor Pressure Model

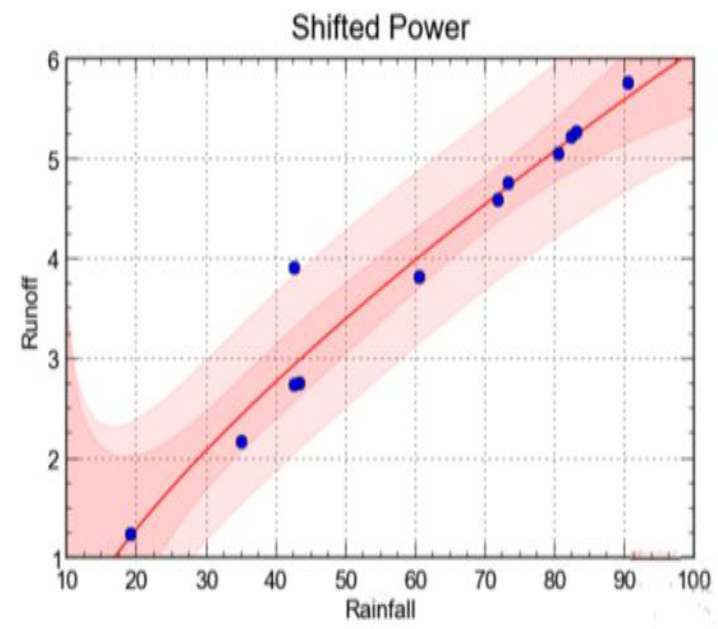

1(b) Shifted Power Model

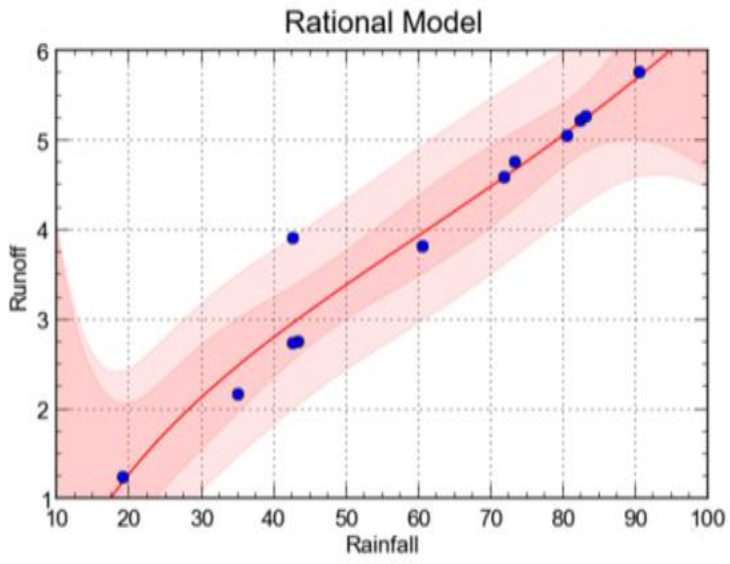

1(d) Rational Model

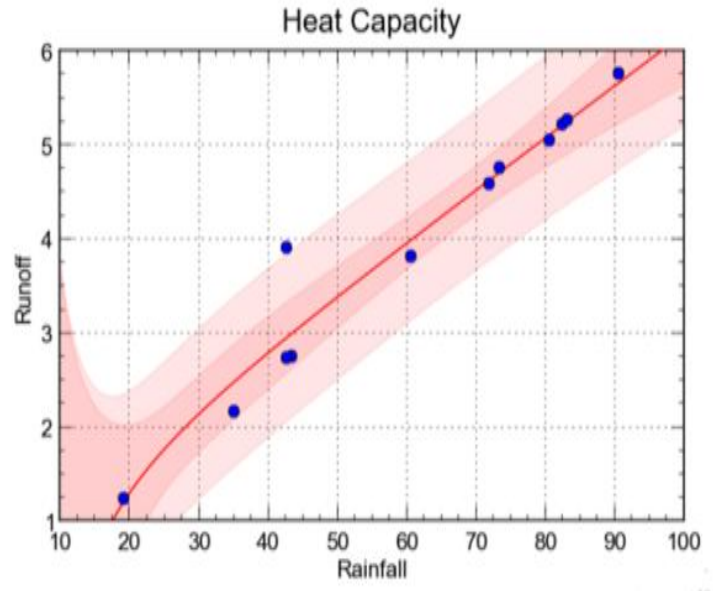

1(e)Heat Capacity Model 


\section{Mean squared error and root mean squared} error

Mean square error and root mean square error was calculated for the models developed for predicting monthly runoff. Table 2 shows mean square error and root mean square error calculated for the models developed for monthly analysis. The values of $\mathrm{R}^{2}$ are high, while the MSE and RMSE values for different models are within permitted limit. The heat capacity model showed highest value of $\mathrm{R}^{2}$ and low value of MSE and RMSE and is the best among all models.

Other models also show small error values with high values of $R^{2}$. These models can also be used for prediction of monthly runoff using rainfall with good results. However, heat capacity model gives results much closer to the actual values. Regression analysis between rainfall and runoff revealed that heat capacity model gives best fit to observed runoff on monthly basis with $\mathrm{R}^{2}$ value 0.948 .

Linear regression model predicted monthly runoff volume with the coefficient of determination value of 0.944 and corresponding Standard error of estimates to be 0.360 .

All the nonlinear models fitted by the software for monthly analysis gives excellent predictions of runoff with coefficient of determination value 0.944 and standard error of estimate 0.357 .

Among all the linear and nonlinear models the most reliable model to predict runoff on both monthly basis was found to be the heat Capacity model based on $\mathrm{R}^{2} 0.948$ and Standard error of estimates 0.357.By the use of model of this nature at least 94 percent of variation in runoff can be explained by rainfall alone.

\section{References}

Austin, C. O. 2006. Storm water runoff quality and quantity from small watersheds in Austin, TX. Water Quality Report Series, COA-ERM/WQM 2006-1.

Chao, Z., Hua-sheng, H., Wei-min, B., and Luoping, Z. Robust recursive estimation of auto-regressive updating model parameters for real-time flood forecasting, Journal of Hydrology, 349, 376-382, 2008.

Cloke, H. and Pappenberger, F. Ensemble flood forecasting: A review, Journal of Hydrology, 375, 613-626, 2009.

King, K.W. 2000. Response of Green-Ampt Mein-Larsen simulated runoff volumes to temporally aggregated precipitation. $J A m$. Water Resource Association, 36(4):791797.

Romanowicz, R. J., Young, P. C., Beven, K. J., and Pappenberger, F. A data based mechanistic approach to nonlinear flood routing and adaptive flood level forecasting, Adv. Water Resource, 31, 1048-1056, 2008.

Smith, K. and Ward, R. Floods: Physical Processes and Human Impacts, John Wiley, Chichester, 1998.

Tiwari, M. K. and Chatterjee, C. Uncertainty assessment and ensemble flood forecasting using bootstrap based artificial neural networks (BANNs), Journal of Hydrology, 382, 20-33, 2010.

Villarini, G., Krajewski, W. F., Ntelekos, A. A., Georgakakos, K. P., and Smith, J. A. Towards probabilistic forecasting of flash floods: the combined effects of uncertainty in radar-rainfall and flash flood guidance, Journal of Hydrology, 394, 275-284, 2010

\section{How to cite this article:}

Mehlath Shah, Syed Midhat Fazil, Syed Rouhullah Ali, Yogesh Pandey, Shahzad Faisal and Iqra Mehraj. 2017. Modeling of Runoff using Curve Expert for Dachigam-Telbal Catchment of Kashmir Valley. Int.J.Curr.Microbiol.App.Sci. 6(11): 3822-3826.

doi: https://doi.org/10.20546/ijcmas.2017.611.449 